\title{
ECOTOXICITY AND CORROSION INHIBITION EFFECT OF QUINOLONIUM AND IMIDAZOLIUM SALTS
}

\author{
${ }^{1}$ Kristýna MARKOVÁ, ${ }^{1}$ Jiří PAVLOVSKÝ, 'Šárka LANGOVÁ, ${ }^{1,2}$ Petr PÁNEK \\ ${ }^{1}$ VŠB - Technical University of Ostrava, 17. listopadu 15/2172, Ostrava 708 33, Czech Republic, EU, \\ kristyna.markova.st@vsb.cz \\ 2Institute of Environmental Technology, VŠB-Technical University of Ostrava, 17. listopadu 15/2172, 70833 \\ Ostrava, Czech Republic, EU
}

https://doi.org/10.37904/metal.2020.3535

\begin{abstract}
The corrosion inhibition of steel in the hydrochloric acid solution by N-butylquinolinium bromide and 1-octyl-3methylimidazolium chloride was investigated using electrochemical and weight loss methods. Both compounds under investigation act as mixed type inhibitors with predominantly anodic action. The Gibbs energy of adsorption was calculated by means of the Langmuir isotherm. The inhibition efficiency of 1-octyl-3methylimidazolium chloride was higher. Daphnia magna was used as acute toxicity test organism. 1-octyl-3methylimidazolium chloride was more toxic than N-butylquinolinium bromide. The $\mathrm{LC}_{50}$ value (48 hours) for 1octyl-3-methylimidazolium chloride for acute test on Daphnia magna was $0.020 \mathrm{mg} \cdot \mathrm{l}^{-1}$ and it was $1.271 \mathrm{mg} \cdot \mathrm{l}^{-1}$ for N-butylquinolinium bromide. 1-octyl-3-methylimidazolium chloride can be classified as extremely toxic substance $\left(\mathrm{LC}_{50}\right.$ is $0.01-0.1 \mathrm{mg} \cdot \mathrm{l}^{-1}$ ) and $\mathrm{N}$-butylquinolinium bromide can be classified as moderate toxic substance ( $\left(C_{50}\right.$ is $\left.1-10 \mathrm{mg} \cdot \mathrm{l}^{-1}\right)$.
\end{abstract}

Keywords: Daphnia magna; N-butylquinolinium bromide; 1-octyl-3-methylimidazolium chloride; corrosion inhibition; steel

\section{INTRODUCTION}

Iron and its alloys belong to the most used building materials due to high mechanical strength and low costs. However, these materials are highly reactive and undergo corrosive degradation during various industrial processes, such as acid cleaning, descaling or acid pickling. Imidazolium compounds are widely studied as corrosion inhibitors for mild steel and other materials. The inhibition efficiency depends on the strength of adsorption. The more negative the Gibbs energy adsorption derived from thermodynamics of the adsorption process, the higher the inhibition potential. The great advantage of ionic liquids (ILs) is the possibility to manage their characteristics through diverse combinations of cations and anions. They exhibit low melting points, negligible vapour pressures, low flammability, high thermal and chemical stability, high electrical conductivity, and high solvation ability for organic and inorganic compounds [1-3]. Some of them are called green solvents but their toxicity has not been sufficiently examined yet. The toxicity of alkylimidazolium ionic liquids usually increases with the increasing alkyl chain length which seems to be related to the high lipophilic character. The anion type also plays an important role but the toxicity impact depends on the tested organism. Acute test on Daphnia magna is usually performed according to ISO 6341 (2012), to determine the inhibition of the mobility of Daphnia magna Straus (acute toxicity test). This is a very sensitive test and is very suitable for these ionic liquids solutions [4-6]. The aim of this study was to compare acute toxicity of $\mathrm{N}$-butylquinolinium bromide and 1-octyl-3-methylimidazolium chloride and to evaluate corrosion inhibition of steel in the hydrochloric acid solution by this ILs. 


\section{EXPERIMENTAL}

\subsection{Materials}

The mild steel wire containing (wt. \%) $0.1 \mathrm{C}, 1.5 \mathrm{Mn}, 0.9 \mathrm{Si}, 0.03 \mathrm{~S}, 0.04 \mathrm{P}$ and balance Fe was used for corrosion measurements. The steel specimens were abraded using various grades of emery papers, washed with distilled water, degreased in acetone and air-dried. The solutions were prepared by dilution of inhibitors in hydrochloric acid of $1000 \mathrm{~mol} \cdot \mathrm{m}^{-3}$ concentration. Ionic liquids were prepared by the microwave synthesis.

\subsection{Ecotoxicity tests}

Ecotoxicity tests on Daphnia magna was done according to ISO 6341 (2012). Daphnia magna organism is a suitable bio-indicator for ecological risk assessments for different or new chemicals and compounds (EC 2002). Ecotoxicological data were calculated as $L_{50}$ values (lethal concentration - mortality of $50 \%$ of individuals), with $95 \%$ confidence intervals calculated by non-linear regression.

\subsection{Electrochemical measurements}

All electrochemical measurements were carried out on Voltalab VM 40, Radiometer Analytical (France). A three-electrode electrochemical system was used with the steel wire as working electrode $\left(0.4 \mathrm{~cm}^{2}\right)$, platinum wire as counter electrode and $\mathrm{Ag} / \mathrm{AgCl}$ in $3 \mathrm{M} \mathrm{KCl}$ as reference electrode. All experiments were performed under atmospheric condition without stirring at $20{ }^{\circ} \mathrm{C}$. Prior to the electrochemical measurements, a stabilization period of $45 \mathrm{~min}$ was allowed, which was proved to be sufficient to attain a quasi-equilibrium state for the open circuit potential (OCP) measurement. The potentiodynamic polarization curves were recorded in the potential range from -150 below to $+150 \mathrm{mV}$ above OCP at a scan rate of $1 \mathrm{mV} \cdot \mathrm{s}^{-1}$ in the positive direction. The EIS measurements were carried out in a frequency range from $100 \mathrm{kHz}$ to $100 \mathrm{mHz}$ with an amplitude of $5 \mathrm{mV}$ peak to-peak, using the AC signal at the OCP.

\subsection{Weight loss measurements}

Gravimetric measurements were performed with the samples prepared in the same way as the working electrode. The wires weighing about $0.2 \mathrm{~g}$ were immersed into the $1000 \mathrm{~mol} \cdot \mathrm{m}^{-3} \mathrm{HCl}$ solution $(20 \mathrm{ml})$ with or without the inhibitor for several days and the weight loss was determined. The inhibition efficiency for the weight loss measurements was calculated from the equation (1), where $W L^{0}$ is the weight loss in $1000 \mathrm{~mol} \cdot \mathrm{m}^{-}$

${ }^{3} \mathrm{HCl}$ solution and $W L^{i}$ is the weight loss in the presence of the inhibitor.

$I E_{W L}=\frac{W L^{0}-W L^{i}}{W L^{0}} \times 100$

\section{RESULTS AND DISCUSSION}

\subsection{Ecotoxicological tests}

The results for acute Daphnia magna test for tested ionic liquids solutions after 48 hours, LC $_{50}$ (in $\mathrm{mg}^{-{ }^{-1}}$ ), with $95 \%$ confidence intervals can be seen in Table 1. The C4QUINBr ionic liquid was less toxic than $\mathrm{C} 8 \mathrm{MImCl}$. According to the study [7], ionic liquid $C 4 \mathrm{QUINBr}$ is moderately toxic and $\mathrm{C} 8 \mathrm{MImCl}$ is extremely toxic. For C4QUINBr the LC 50 value for Daphnia magna (48 hours) is $1.271 \mathrm{mg} \cdot \mathrm{l}^{-1}$ and for C8MImCl the LC 50 value is $0.020 \mathrm{mg} \cdot \mathrm{l}^{-1}$. The nonlinear curves of mortality depending on the molar concentration of ionic liquids solutions are represented in Figures 1-2. 
Table 1 Results for acute Daphnia magna test of ionic liquids solutions, 48 hours, $\mathrm{LC}_{50}\left(\mathrm{mg} \cdot \mathrm{I}^{-1}\right)$ and hazard ranking, $95 \%$ confidence intervals

\begin{tabular}{|c|c|c|c|}
\hline $\begin{array}{c}\text { Ionic liquids } \\
\text { solutions }\end{array}$ & $\begin{array}{c}\mathbf{L C}_{50} \\
\left(\mathbf{m g} \cdot \mathrm{I}^{-1}\right)\end{array}$ & $\begin{array}{c}\text { Lower limit-upper limit } \\
\left(\mathbf{m g} \cdot \mathrm{I}^{-1}\right)\end{array}$ & $\begin{array}{c}\text { Hazard ranking }^{+} \\
\text {(according to [7]) }\end{array}$ \\
\hline C8MImCl & 0.020 & $0.011-0.029$ & extremely toxic \\
\hline C4QUINBr & 1.271 & $0.549-6.315$ & moderately toxic \\
\hline
\end{tabular}

${ }^{+} \mathrm{LC}_{50}$ is $0.01-0.1 \mathrm{mg} \cdot \mathrm{l}^{-1}$ - extremely toxic, $0.1-1 \mathrm{mg} \cdot \mathrm{l}^{-1}$ - highly toxic, $\mathrm{LC}_{50}$ is $1-10 \mathrm{mg} \cdot \mathrm{l}^{-1}$ - moderately toxic, $\mathrm{LC}_{50}$ is $10-100 \mathrm{mg} \cdot \mathrm{l}^{-1}$ - slightly toxic and LC 50 is $100-1000 \mathrm{mg} \cdot \mathrm{l}^{-1}$ - harmless (non-toxic)

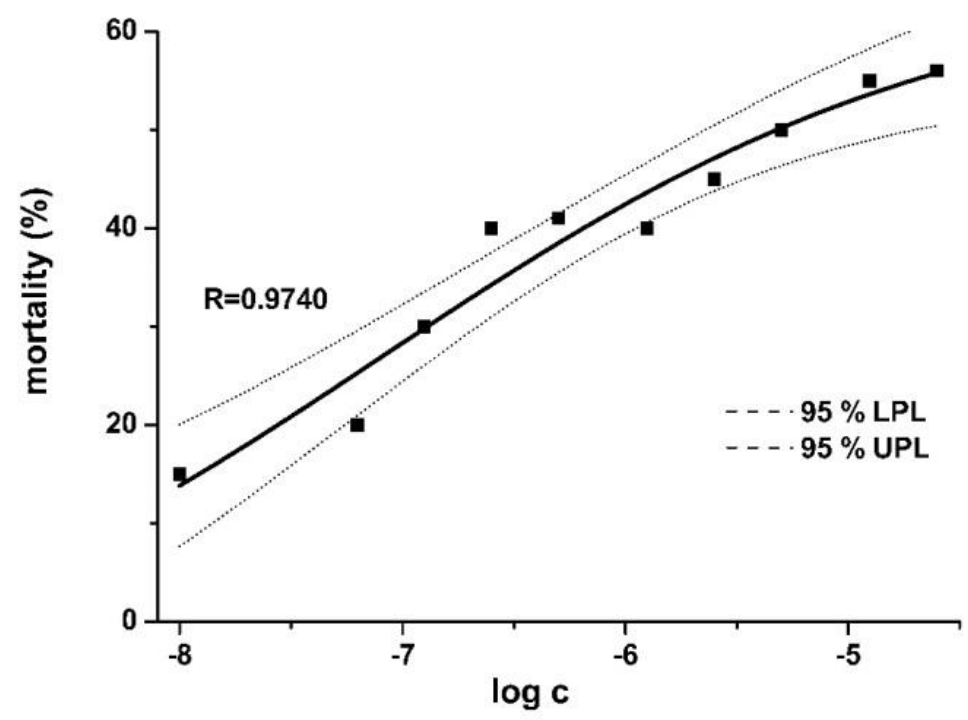

Figure 1 Nonlinear curves of mortality depending on concentration for C4QUINBr, acute Daphnia magna test, $48 \mathrm{~h}$

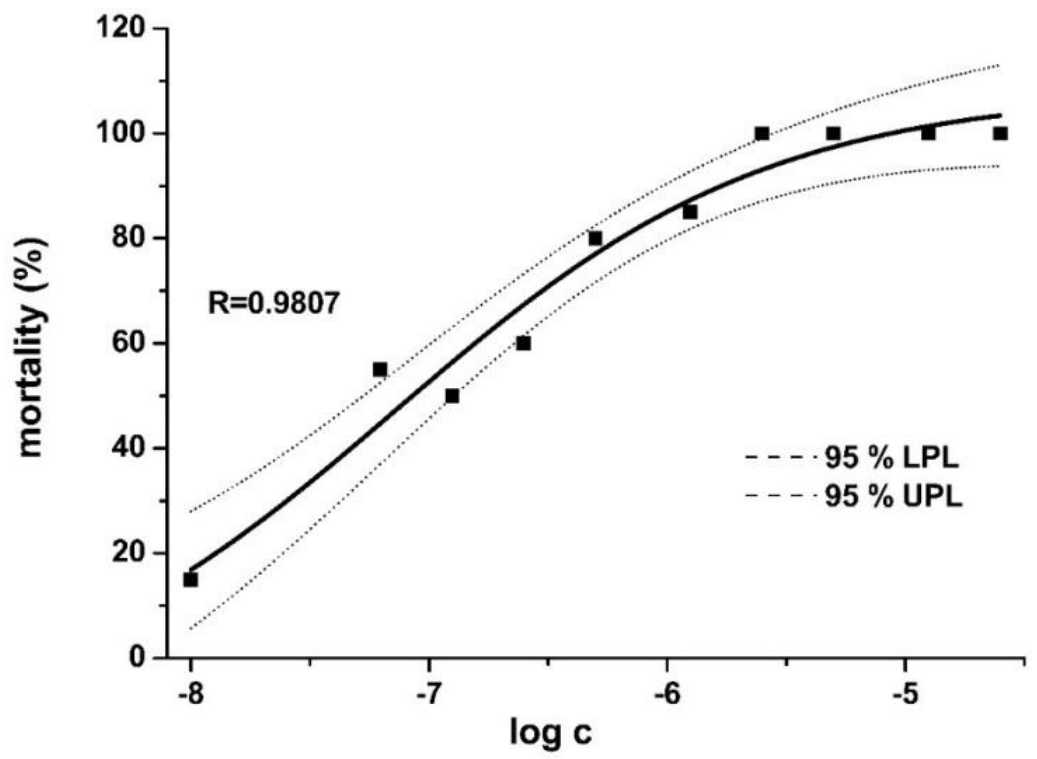

Figure 2 Nonlinear curves of mortality depending on concentration for $\mathrm{C} 8 \mathrm{MImCl}$, acute Daphnia magna test, 


\subsection{Potentiodynamic polarization curves and electrochemical impedance spectroscopy}

Figure 3 presents potentiodynamic polarization curves of corrosion inhibition of mild steel in $1000 \mathrm{~mol} \cdot \mathrm{m}^{-3} \mathrm{HCl}$ in the absence and presence of C4QUINBr. The corrosion potential is shifted slightly to the positive direction depending on the inhibitor concentration. Because of the difference is less than $85 \mathrm{mV}, \mathrm{C} 4 \mathrm{QUINBr}$ can be classified as mixed type inhibitor with a predominant anodic action. The same trend can also be observed for $\mathrm{C} 8 \mathrm{MImCl}$. Inhibition efficiency $\left(\mathrm{IE}_{\mathrm{i}}\right)$ is dependent on the inhibitor concentration, the values are reported in Table 2.

The EIS measurements were evaluated by means of EIS analyser software. Figure 4 presents Nyquist plots of corrosion inhibition of mild steel in $1000 \mathrm{~mol} \cdot \mathrm{m}^{-3} \mathrm{HCl}$ in the absence and presence of C4QUINBr. The values of inhibition efficiency (IEEIS) obtained from EIS measurements are presented in Table 2. The differences between the voltammetric and EIS measurements can be explained by the unequal time of measurement.

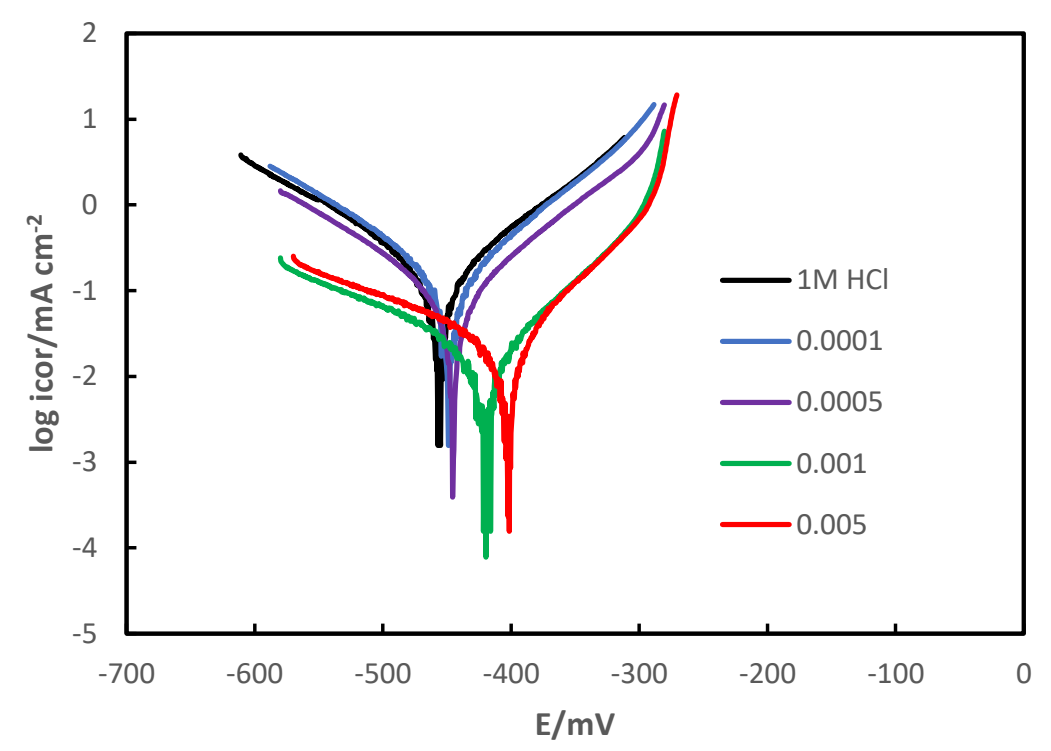

Figure 3 Potentiodynamic polarization curves of corrosion inhibition of mild steel in $1000 \mathrm{~mol} \cdot \mathrm{m}^{-3} \mathrm{HCl}$ in the absence and presence of $\mathrm{N}$-butylquinolinium bromide

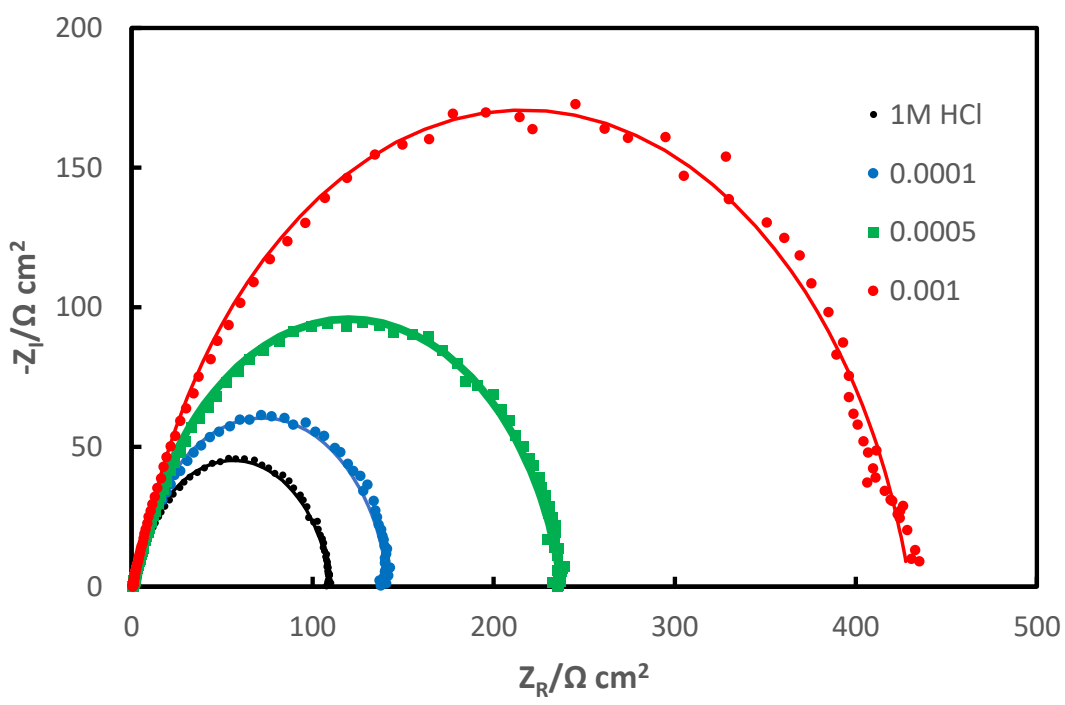

Figure 4 Nyquist plots of corrosion inhibition of mild steel in $1000 \mathrm{~mol} \cdot \mathrm{m}^{-3} \mathrm{HCl}$ in the absence and presence of $\mathrm{N}$-butylquinolinium bromide 
Table 2 Inhibition efficiency for mild steel in $1000 \mathrm{~mol} \cdot \mathrm{m}^{-3} \mathrm{HCl}$ solution in the absence and presence of $\mathrm{N}$ butylquinolinium bromide and 1-octyl-3-methylimidazolium chloride at $20^{\circ} \mathrm{C}$ obtained from electrochemical measurements and weight loss measurements

\begin{tabular}{|c|c|c|c|c|}
\hline & $\mathbf{c}\left(\mathbf{m o l ~ d m}^{-3}\right)$ & IE (\%) & IEEIS (\%) & IEwL (\%) \\
\hline \multirow{3}{*}{ C4QUINBr } & 0.0001 & 25 & 36 & 20 \\
\cline { 2 - 5 } & 0.001 & 89 & 79 & 66 \\
\cline { 2 - 5 } & 0.005 & 90 & 90 & 81 \\
\hline \multirow{3}{*}{ C8MImCl } & 0.0001 & 62 & 67 & 80 \\
\cline { 2 - 5 } & 0.001 & 86 & 92 & 96 \\
\cline { 2 - 5 } & 0.005 & 86 & 90 & 94 \\
\hline
\end{tabular}

\subsection{Weight loss measurements and adsorption isotherms}

The results of the weight loss measurements (IEWL) after seven days are shown in Table 2.

The adsorption of inhibitors never reaches the real equilibrium but tends to approach an adsorption steady state. The values of surface coverage, $\Theta(\mathrm{IE} / 100)$ for the different concentration of C4QUINBr and C8MImCI proved to fit Langmuir adsorption isotherm (2). $C$ is the molar concentration of the inhibitor and $K$ is the equilibrium constant of the adsorption reaction. The absolute values of Gibbs energies can be seen in Table 3. The interaction between the inhibitor and metal surface probably involves both physisorption and chemisorption. Although Langmuir isotherm is usually used for chemisorption, in case of monolayer physisorption can be involved.

$\frac{c}{\theta}=C+\frac{1}{K}$

The results obtained from the voltammetric and weight loss measurements can be seen in Figure 5 .

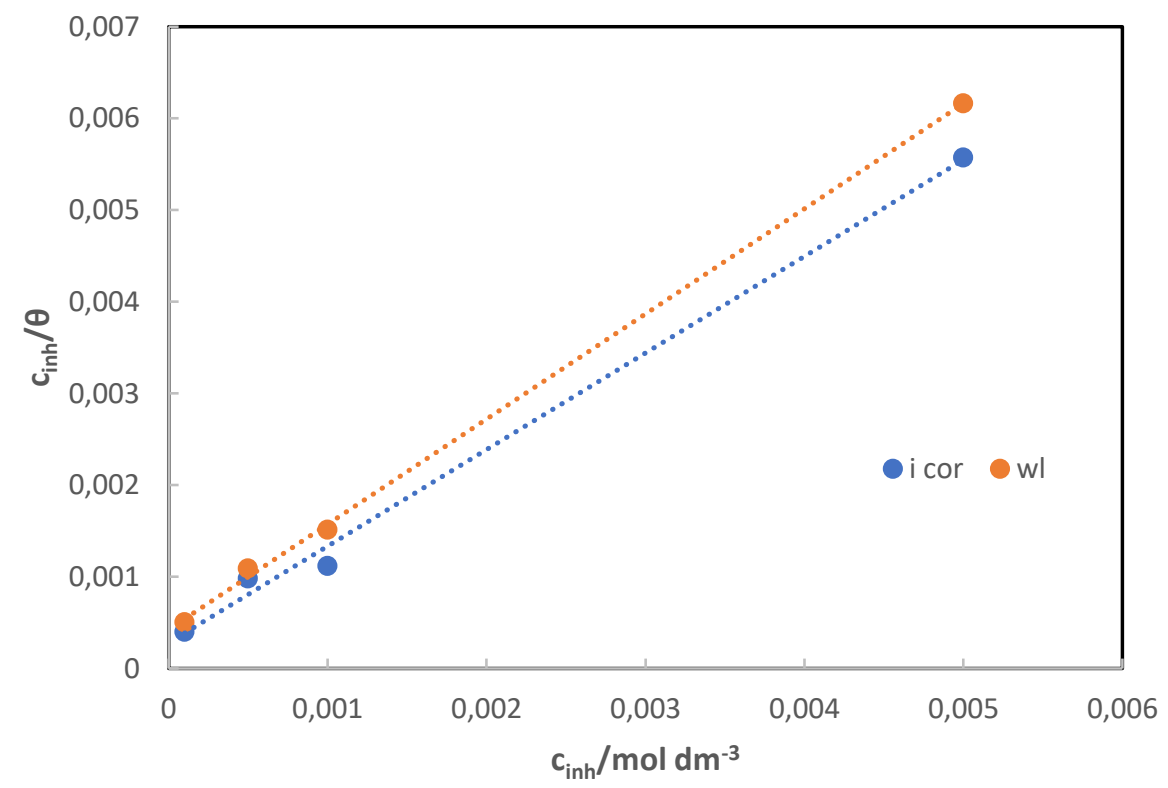

Figure 5 Curve fitting of the data obtained from polarization curves ( $\mathrm{i}$ cor) and weight loss (wl) measurements to Langmuir isotherm for mild steel in $1000 \mathrm{~mol} \cdot \mathrm{m}^{-3} \mathrm{HCl}$ and $\mathrm{N}$-butylquinolinium bromide 
Table 3 Gibbs energy of adsorption obtained from Langmuir isotherms $\left(\mathrm{kJ} \cdot \mathrm{mol}^{-1}\right)$.

\begin{tabular}{|c|c|c|}
\hline & $\mathbf{i}_{\text {cor }}$ & wl \\
\hline C4QUINBr & -29.5 & -28.8 \\
\hline C8MImCl & -37.8 & -35.1 \\
\hline
\end{tabular}

\section{CONCLUSION}

The acute toxicity of $\mathrm{N}$-butylquinolinium bromide and 1-octyl-3-methylimidazolium chloride was measured using Daphnia magna Straus test, 48 hours. It was found that $\mathrm{C} 4 \mathrm{QUINBr}$ is moderately toxic and $\mathrm{C} 8 \mathrm{MImCl}$ is extremely toxic. For C4QUINBr the $\mathrm{LC}_{50}$ value for Daphnia magna is $1.271 \mathrm{mg}^{-1} \mathrm{I}^{-1}$ and for $\mathrm{C} 8 \mathrm{MImCl}$ the $\mathrm{LC}_{50}$ value is $0.020 \mathrm{mg} \cdot \mathrm{l}^{-1}$.

The corrosion inhibition efficiency of the $C 4 Q U I N B r$ and $C 8 M I m C l$ was investigated by means of the potentiodynamic polarization curves, EIS and weight loss measurements. Both ionic liquids were proved to be mixed-type inhibitors with the predominant anodic inhibitive effect for the mild steel. The inhibition efficiency of both ionic liquids is about $90 \%$ for the highest concentration $5 \mathrm{~mol} \cdot \mathrm{m}^{-3}$. The inhibition efficiency decreases with decreasing concentration of ionic liquid. A more significant decline can be seen for C4QUINBr. The absolute values of Gibbs energies of adsorption obtained from the Langmuir isotherms ranged from 28.8 to $29.5 \mathrm{~kJ} \cdot \mathrm{mol}^{-1}$ for $\mathrm{C} 4 \mathrm{QUINBr}$ and from 35.1 to $37.8 \mathrm{~kJ} \cdot \mathrm{mol}^{-1}$ for $\mathrm{C} 8 \mathrm{MImCl}$. The interaction between the inhibitor and metal surface probably involves both physisorption and chemisorption.

\section{ACKNOWLEDGEMENTS}

This work was financially supported by the Ministry of Industry and Trade, project No. FV10089 Synthesis of ionic liquids in microwave reactor. Experimental results were accomplished by using Large Research Infrastructure ENREGAT supported by the Ministry of Education, Youth and Sports of the Czech Republic under project No. LM2018098. This work was also financed by the project of Specific research: SP 2018/79 and SP 2018/60.

\section{REFERENCES}

[1] YESUDASS, S., OLASUNKANMI, L.O., BAHADUR, I., et al. Experimental and theoretical studies on some selected ionic liquids with different cations/anions as corrosion inhibitors for mild steel in acidic medium. Journal of Tawain Institute of Chemical Engineers. 2016, vol. 64, pp. 252-268.

[2] ZHANG, Q. B., HUA, Y. X. Corrosion inhibition of mild steel by alkylimidazolium ionic liquids in hydrochloric acid. Electrochimica Acta. 2009, vol. 54, pp. 1881-1887.

[3] GUO, Y., XU, B., LIU Y., et al. Corrosion inhibition properties of two imidazolium ionic liquids with hydrophilic tetrafluoroborate and hydrophobic hexafluorophosphate anions in acid medium. Journal of Industrial and Engineering Chemistry. 2017, vol. 56, pp. 234-247.

[4] BICZAK, R., PAWŁOWSKA, B., BAŁCZEWSKI, P., RYCHTER, P. The role of the anion in the toxicity of imidazolium ionic liquids. Journal of Hazardous Materials. 2014, vol. 274, pp. 181-190.

[5] COSTA, S.P.F., PINTO, C.A.G.P., SARAIVA, M.F.S.L., et al. The aquativ impact of ionic liquids on freshwater organisms. Chemosphere. 2015, vol. 139, pp. 288-294.

[6] STOLTE, S., STEUDTE, S., AREITIOAURTENA, O., et al. Ionic liquids as lubricants or lubrication additives: An ecotoxicity and biodegradability assessment. Chemosphere. 2012, vol. 89, pp. 1135-1141.

[7] PASSINO, D.R.M., SMITH, S.B. Acute bioassays and hazard evaluation of representative contaminants detected in great lakes fish. Environmental Toxicology and Chemistry. 1987, vol. 6, pp. 901-907. 